[19] Feng, F., Xiang, Y. (2010). Surgical management of chemotherapy-resistant gestational trophoblastic neoplasia. Expert Review of Anticancer Therapy, 10 (1), 71-80. doi: 10.1586/era.09.169

[20] Kozarenko, T. M., Tsip, N. P., Medvedev, V. E. et. al. (2004). The possibilities of magnetic resonance imaging and color Doppler mapping in monitoring the efficacy of trophoblastic tumor treatment. Women's health, 2 (18), 99-103.

[21] Feng, F., Xiang, Y., Li, L., Wan, X., Yang, X. (2009). Clinical parameters predicting therapeutic response to surgical management in patients with chemotherapy-resistant gestational trophoblastic neoplasia. Gynecologic Oncology, 113 (3), 312-315. doi: 10.1016/j.ygyno.2009.02.025

[22] Lurain, J. R. (2011). Gestational trophoblastic disease II: classification and management of gestational trophoblastic neoplasia. American Journal of Obstetrics and Gynecology, 204 (1), 11-18. doi: 10.1016/ j.ajog.2010.06.072

\title{
DIAGNOSTICS OF CHRONIC OBSTRUCTIVE PULMONARY DISEASE IN REAL CLINICAL PRACTICE: HYPODIAGNISTICS OR HYPERDIAGNOSTICS
}

\author{
Nataliya Cherepii \\ Department of propedeutics of internal medicine \\ Vinnytsia National M. I. Pirogov Memorial Medical University \\ 56 Pyrogov str., Vinnytsia, Ukraine, 21018 \\ nataliya_cherepii@mail.ru \\ Lesia Rasputina \\ Department of propedeutics of internal medicine \\ Vinnytsia National M. I. Pirogov Memorial Medical University \\ 56 Pyrogov str., Vinnytsia, Ukraine, 21018
}

\begin{abstract}
According to the data of the world statistics there is observed the continuous growth of chronic obstructive pulmonary disease (COPD). According to the last data of the World health organization (WHO), for today there is near $250 \mathrm{mln}$ persons with chronic obstructive pulmonary disease (COPD), and this disease becomes as cause of death of near $3 \mathrm{mln}$ persons annually.

Aim: to establish the prevalence of undiagnosed chronic pulmonary disease (COPD) among persons, who consider themselves as healthy ones and regularly undergo medical check-ups; to estimate the frequency of chronic obstructive pulmonary disease (COPD) according to the data of medical documentation.

Methods and materials: 525 persons, older than 35, who did not have in an anamnesis any chronic diseases of respiratory tract, were interrogated. At the following stage, persons, who had taken 18 points or more underwent a spirography with bronchodilatation test, using $400 \mathrm{mcg}$ of salbutamol and were interrogated by the modified questionnaire of short breath by the medical research council (MRC) and test of the chronic obstructive pulmonary disease estimation (COPD) (TEC). There were examined 136 patients, mean age $(51,5 \pm 0,8)$, men were $81(59,5 \%)$ mean age $(52,2 \pm 1,1)$ and women $-55(40,4 \%)$ mean age $(50,7 \pm 0,9)$.

There were analyzed 56 medical stories of patients, treated at therapeutic departments of the city clinic because of internal organs diseases with the concomitant diagnosis of chronic obstructive pulmonary disease (COPD).

Among persons with first revealed chronic obstructive pulmonary disease y 21 (26,6 \%) was reveled I severity degree according to GOLD, in 26 persons (32,9\%) - GOLD II, in $28(35,4 \%)$ - GOLD III, in 4 (5,1 \%) - GOLD IV severity degree, so 32 patients did not receive basic treatment at all.
\end{abstract}


At the same time among patients with COPD diagnosis in medical documentation only in $38,4 \%$ this diagnosis was spirographically verified, the hyperdiagnostics of disease on the base of complaints and age characteristic took place in other cases.

Keywords: chronic obstructive pulmonary disease (COPD), hypodiagnostics of chronic obstructive pulmonary disease (COPD), intensification of chronic obstructive pulmonary disease (COPD), spirography.

\section{Introduction}

According to the data of the world statistics there is observed the continuous growth of chronic obstructive pulmonary disease (COPD). According to the last data of the World health organization (WHO), for today there is near $250 \mathrm{mln}$ persons with chronic obstructive pulmonary disease (COPD), and this disease becomes as case of death of near $3 \mathrm{mln}$ persons annually [1, 2]. Morbidity of chronic obstructive pulmonary disease (COPD) is growing. According to the data of European respiratory society (ERS) its growth is predicted up to 2020, when is will occupy the 4 place after such diseases as IHF, cerebrovascular pathology, lung cancer - such tendency is typical for both Eastern and Western Europe. World health organization prognoses that up to 2030 chronic obstructive pulmonary disease (COPD) will be the third most spread cause of death after myocardium infarction and stroke $[3,4]$.

The one of unsolved questions of the chronic obstructive pulmonary disease (COPD) prevalence is an absence of real statistical data, because its diagnostics is usually realized at clinically significant stages that is at III-IV-th ones, whereas patients at I and II stages are medically examined seldom, don't receive a treatment that favors the pathological state progression, complications development, essential costs for treatment and morbidity growth [5,6]. This problem is urgent for Ukraine and throughout the world. It is proved by the study of Sweden scientists, who realized the screening determination of external respiratory function (ERF) among patients of 40-75 years old, admitted to a hospital because of acute respiratory infections. It was established, that in general $27 \%$ had previously undiagnosed chronic obstructive pulmonary disease (COPD), moreover in $45 \%$ of patients was revealed I stage of the chronic obstructive pulmonary disease (COPD), in $53 \%$ of patients - II stage, in $3 \%$ - III stage of the chronic obstructive pulmonary disease (COPD), and patients with IV stage of the chronic obstructive pulmonary disease (COPD) were absent [7, 8]. So, despite the epidemiological prevalence of chronic obstructive pulmonary disease (COPD), there is an essential part of patients, who don't know about its existence, so don't realize any treating and prophylactic arrangements, recommended for delaying the disease progression and decreasing the complications number $[9,10]$.

So, the works that demonstrate the true prevalence of undiagnosed chronic obstructive pulmonary disease (COPD), elaborate the algorithms of diagnostics and selection of patients for further examination are urgent and modern.

\section{Aim of research}

To establish the prevalence of undiagnosed chronic obstructive pulmonary disease (COPD) among patients, who consider themselves as healthy ones and regularly undergo medical checkups; to estimate the frequency of chronic obstructive pulmonary disease (COPD) according to the data of medical documentation.

\section{Materials and methods}

The interrogation was carried out using the original questionnaire, created on the base of GOLD forms $(2012,2015)$ and the order of health protection ministry of Ukraine No. 555 of 27.06.2013 [5, 11, 12]. 525 persons, older than 35 , who did not have in an anamnesis any chronic diseases of respiratory tract, were interrogated; mean age $(46,7 \pm 6,3)$ years, among them 291 $(55,4 \%)$ men, mean age $(46,7 \pm 6,3)$ years, women $-234(44,6 \%)$, mean age $-(56,7 \pm 4,7)$ years. All interrogated persons worked in an organized collective and underwent medical check-ups regularly twice a year. 
At the following stage, persons, who had complaints, typical for the chronic obstructive pulmonary disease underwent a spirography with bronchodilatation test, using $400 \mathrm{mmcg}$ of salbutamol and were interrogated by the modified questionnaire of short breath by the medical research council (MRC) and test of chronic obstructive pulmonary disease estimation (TEC) to determine the clinical group of chronic obstructive pulmonary disease that is regulated by the order of the health protection ministry of Ukraine № 555 of 27.05.2013 [11, 13]. There were examined 136 patients, mean age $(51,5 \pm 0,8)$, men were $81(59,5 \%)$ mean age $(52,2 \pm 1,1)$ and women $-55(40,4 \%)$ mean age $(50,7 \pm 0,9)$.

There were analyzed 56 medical stories of patients, treated at therapeutic departments of Vinnitsia city clinic because of internal organs diseases with the concomitant diagnosis of chronic obstructive pulmonary disease.

The characteristic of examined persons is presented in the Table 1.

Table 1

Characteristic of examined persons with the diagnosis chronic obstructive pulmonary disease

\begin{tabular}{cc}
\hline Sign & Number \\
\hline Totally & 56 \\
Mean age, years & $65,4 \pm 3,1$ \\
Men & $34(60,7 \%)$ \\
Women & $22(39,3 \%)$ \\
Cardiovascular diseases & $35(62,5 \%)$ \\
Gastrointestinal diseases & $21(37,5 \%)$ \\
Diabetes mellitus & $25(44,6 \%)$
\end{tabular}

All patients underwent a computer spirography with bronchodilatation test, using $400 \mathrm{mcg}$ of salbutamol and were interrogated by the modified questionnaire of short breath by thrmedical research council (MRC) and test of the chronic obstructive pulmonary disease estimation (TEC) to determine the clinical group of chronic obstructive pulmonary disease $[14,15]$.

The statistical processing of received data were carried out on a personal computer using variational statistic methods with the program MicroSoftExel 2003 iStatSoft,,Statistica” v.6.1, (Licence version №BXXR901E246022FA owned by the medical-diagnostic center of Vinnitsia national medical university, named after M. I. Pirogov) [16]. The results at a probability error $<0,05$ were considered as reliable ones.

\section{Results of research}

At the stage of interrogation it was established that the symptoms, typical for the chronic obstructive pulmonary disease were demonstrated by 216 persons $(41,2 \%)$, at that the diagnosis of chronic obstructive pulmonary disease was not set to none of them. Women were 115 (53,2 \%), men - 101 (46.8\%), among both men and women prevailed persons older than 50 years [17].

According to the questions of questionnaire, we established that examined patients have most often complaints of cough, short breath, often catarrhal disease of respiratory tracts and episodes of whistling breath. It was established, that $203(94 \%)$ examined persons complained of cough, among them 112 women (55,2\%) and 91 men (44,8\%). 195 (90,3\%) among examined persons complained of short breath at physical loads, among them 109 women ( 55,9\%) and men 86 men (44,1 \%) (Fig. 1). The frequency of catarrhal diseases of respiratory organs was distributed as following among interrogated persons during the last year: totally 96 (44,4 \%) once a year complained of the frequent catarrhal diseases of respiratory organs, among them $57(59,4 \%)$ men and $39(60,6 \%)$ women; twice a year - $74(34,3 \%)$ totally, among them $32(43,2 \%)$ men and $42(56,8 \%)$ women; thrice a year - $32(14,8 \%)$ totally, among them $8(25,0 \%)$ men and $24(75,0 \%)$ women; 4 times a year - $13(6,0 \%)$ totally, among them 4 (30,8\%) men and 9 (69,2\%) women; 5 times 
a year - $1(0,5 \%)$ woman. It was established, that $148(68,5 \%)$ persons complained of whistling breath, felling of compression in breast, among them $83(56,1 \%)$ women and $65(43,9 \%)$ men.

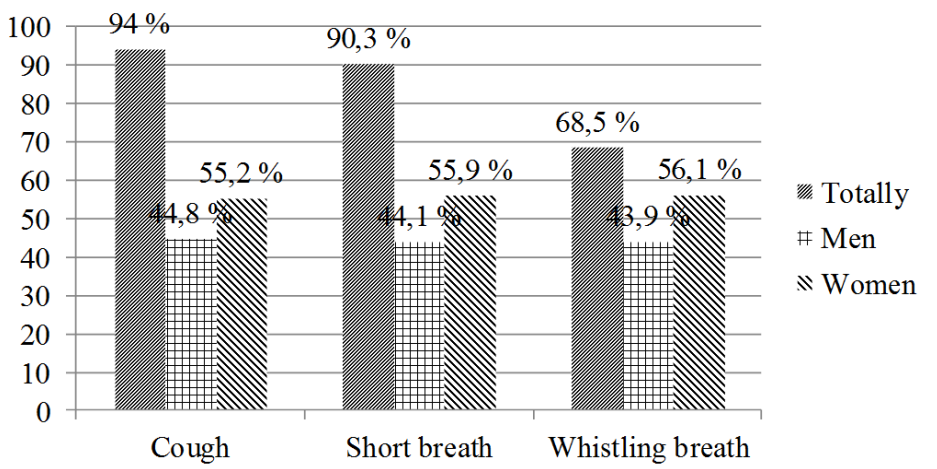

Fig. 1. Prevalence of COPD symptoms according to interrogation data

It was established that 79 (58,1\%) among interrogated persons had fist diagnosed chronic obstructive pulmonary disease of I-IV severity degrees. 57 patients $(41,9 \%)$ had the diagnosis of chronic obstructive pulmonary disease COPD, not verified by the spirography results (Fig. 2). Women were 31 (39,2\%), men - 48 (60,8 \%).

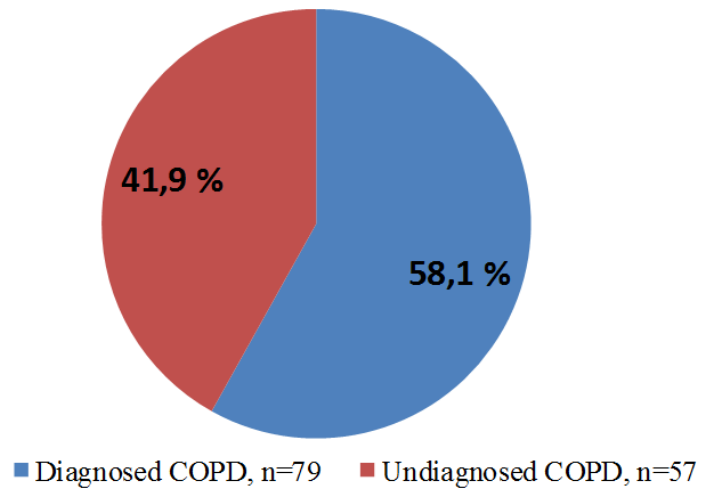

Fig. 2. Part of diagnosed COPD after spirogfraphy in patients, who had 18 and more points according to the interrogation results

\section{Discussion of research results}

Among persons with first diagnosed COPD is observed the tendency to growth of persons of something older age, respectively: $52,2 \pm 1,1$ and $50,4 \pm 0,9$ at $p=0,23$. In this group smokers including former ones occurred reliably more often, respectively: $53(67,1 \%)$ and $28(49,2 \%), p=0,03$. In persons with first revealed chronic obstructive pulmonary (COPD) the complicated family anamnesis was diagnosed in $41(59,1 \%)$ patients as opposite to persons without this disease $27(47,2 \%)$, $\mathrm{p}=0,69$ (Table 2).

At the same time patients with COPD had more HR as opposite to ones without the chronic obstructive pulmonary disease, respectively: 74 (70;82) and $70(70 ; 78), p=0,04$; MRC short breath, respectively: $1,44 \pm 0,07$ points and $0,96 \pm 0,09$ points, $\mathrm{p}=0,0001$, number of points by TEC scale: $18,8 \pm 0,8$ and $12,7 \pm 1,0, \mathrm{p}=0,0001$ respectively.

It also must be noted that among patients with first diagnosed chronic obstructive pulmonary disease (COPD) in $21(26,6 \%)$ was revealed I severity degree according to GOLD, in 26 persons $(32,9 \%)$ - GOLD II, in $28(35,4 \%)$ - GOLD III, in $4(5,1 \%)$ - GOLD IV (Fig. 3).

So, in patients, who have complaints of cough, short breath, whistling breath and often respiratory diseases at regular medical check-ups, the chronic obstructive pulmonary disease was first revealed in 79 persons $(14,3 \%)$. 
Table 2

Clinical features in patients with first diagnosed chronic obstructive pulmonary disease

\begin{tabular}{|c|c|c|c|}
\hline Sign & $\begin{array}{l}\text { Patients with diagnosed COPD, } \\
\qquad \mathbf{n}=79\end{array}$ & $\begin{array}{l}\text { Patients without diagnosed } \\
\text { COPD, } \mathbf{n}=\mathbf{5 7}\end{array}$ & $\mathbf{P}$ \\
\hline Men & $48(60,8 \%)$ & $33(57,9 \%)$ & 0,66 \\
\hline Women & $31(39,2 \%)$ & $24(42,1 \%)$ & 0,73 \\
\hline Age, years & $52,2 \pm 1,1$ & $50,4 \pm 0,9$ & 0,23 \\
\hline Complicated family anamnesis & $41(59,1 \%)$ & $27(47,2 \%)$ & 0,69 \\
\hline Smoking (including former) & $53(67,1 \%)$ & $28(49,2 \%)$ & 0,03 \\
\hline $\mathrm{HR}$, str in min & $74(70 ; 82)$ & $70(70 ; 78)$ & 0,04 \\
\hline MBI, $\mathrm{kg} / \mathrm{m}^{2}$ & $27,7(24,5 ; 32,3)$ & $30,8(26,0 ; 33,8)$ & 0,03 \\
\hline MRC, points & $1,44 \pm 0,07$ & $0,96 \pm 0,09$ & 0,0001 \\
\hline SAP test, points & $18,8 \pm 0,8$ & $12,7 \pm 1,0$ & 0,0001 \\
\hline
\end{tabular}

Patients' distribution depending on severity degree

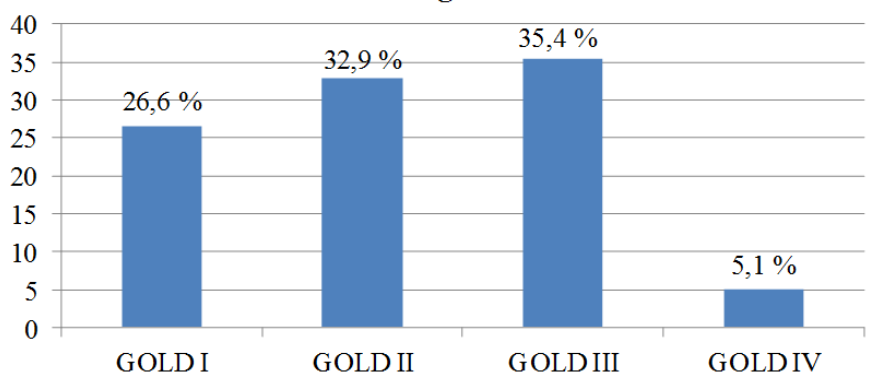

Fig. 3. Distribution of patients with chronic obstructive pulmonary disease depending on severity degree according to GOLD

At the same time the analysis of medical documentation allowed to reveal that the chronic obstructive pulmonary disease as a concomitant disease is diagnosed by doctors of general practice not soundly rather often.

Among 56 persons, treated at therapeutic departments of the city hospital 18 persons $(32,1 \%)$ had complaints of cough, short breath was observed by 42 patients (75\%), whistling breath episodes - by 12 persons $(21,4 \%)$ and $26(46,4 \%)$ observed frequent respiratory diseases. 18 persons $(32,1 \%)$ smoked (including former smokers), the contact with professional harmful factors was observed by 11 patients (19,6\%) (seamstresses, welders), the hereditary anamnesis was complicated in 7 persons $(12,5 \%)$. Thus, the main complaint that the diagnosis of chronic obstructive pulmonary disease (COPD) was based on was a short breath.

Before the spirographic examination we have interrogated all patients as to the spirography experience in past. It was established, that only 4 patients $(7,1 \%)$ underwent a spirography earlier. So, it is not a routine method of diagnostics in doctors of general practice that is a violation of requirements as to diagnostics of chronic obstructive pulmonary disease (COPD), regulated by the order of the health protection ministry of Ukraine No. 555 of 27.05.2013.

We realized a spirography with bronchodilatation test using $400 \mathrm{mcg}$ of salbutamol. The diagnosis of chronic obstructive pulmonary disease (COPD) was verified in 32 persons (57,1\%), 8 women $(25 \%)$ and 24 men $(75 \%),(p=0,005)$. Depending on the severity degree the persons with COPD were distributed as following: GOLD were revealed in 4 persons $(12,5 \%)$, GOLD II - in 12 patients $(37,5 \%)$, GOLD III - 14 patients $(43,7 \%)$ and GOLD IV - in 2 patients $(6,3 \%)$. 
Patients with chronic obstructive pulmonary disease (COPD) after interrogation by the modified estimation of short breath by the medical research council (MRC) and test of chronic obstructive pulmonary disease estimation (TEC) were distributed as following: short breath degree was $1,94 \pm 0,09$ points, in women $-2,17 \pm 0,07$, in men $-0,95 \pm 0,05,(p=0,05)$. According to COPD estimation in all interrogated persons were observed $19,8 \pm 0,7$ points, among women $-18,6 \pm 0,6$, among men $-20,9 \pm 0,78,(p=0,02)$, Table 3 .

Table 3

Short breath degree and the results of test in persons with verified disease

\begin{tabular}{|c|c|c|c|}
\hline Sign & Totally, $n=32$ & Women, $n=8$ & Men, $n=24$ \\
\hline MRC, points & $1,94 \pm 0,09$ & $2,17 \pm 0,07$ & $0,95 \pm 0,05$ \\
\hline SAP test, points & $19,8 \pm 0,7$ & $18,6 \pm 0,6$ & $20,9 \pm 0,78$ \\
\hline
\end{tabular}

The problem of diagnostics and treatment of the chronic obstructive pulmonary disease (COPD) are argued by the order of the health protection ministry of Ukraine № 555 of 27.06.2013, according to which, the chronic obstructive pulmonary disease (COPD) it is a widespread disease that may be prevented and treated, characterized by the stable, usually progressing limitation of respiratory tracts permeability and associated with the increased chronic inflammatory response of respiratory tracts and lungs on the effect on harmful particles and gases [18].

Despite the essential informational activity, wide introduction of spirography, the problem of the chronic obstructive pulmonary disease (COPD) diagnostics remains the one of urgent problems. There must be separated the following factors that favor untimely diagnostics or hyperdiagnostics of this disease [19, 20]:

At first, at appearance of such symptoms as short breath and cough, patients don't immediately address for medical help, often considering them as a usual state, taking into account the gradual progression of this disease.

At second, these symptoms are often associated with the development of cardiovascular diseases symptoms that is caused by the fact that these very diseases are manifested in persons older 40 years as well as the chronic obstructive pulmonary disease (COPD).

At third, most doctors of general practice underestimate the importance of risk factors that favors the diagnostics of chronic obstructive pulmonary disease (COPD) of the middle and heavy severity in most cases.

It must be also noted that patients, whose diagnosis of the chronic obstructive pulmonary disease (COPD) was set only on the base of clinical signs without a spirographic confirmation, received drugs that did not cause relief, mainly beta2-agonists of the short action.

At the same time doctors of general practice, having knowledge about the diagnostics of chronic obstructive pulmonary disease (COPD), often neglect the estimation of risk factors and spirographic method that also leads to hypediagnostics of this disease at leaving beyond attention persons, who really need a treatment and prophylaxis of the chronic obstructive pulmonary disease (COPD).

\section{Conclusions}

1. The diagnostics of chronic obstructive pulmonary disease (COPD) belongs to most urgent and complicated ones in the work of a doctor of general practice that is determined on the one side by the increase of the number of persons of older age groups that have a series of risk factors, on the other one by the increase of methodological approaches as to the diagnostics of this disease.

2. We have established that in a collective of persons, who undergo medical check-ups, the undiagnosed chronic obstructive pulmonary disease (COPD) is revealed in 79 persons $(14,3 \%)$, in 31 women (39,2\%) and 48 men (60,8\%). Most often patients with first revealed chronic obstructive 
pulmonary disease (COPD) had complaints of cough, short breath, whiling breath and frequent respiratory diseases.

3. In patients with first revealed disease in $21(26,6 \%)$ was revealed I severity degree according to GOLD, in 26 persons (32,9\%) - GOLD II, in $28(35,4 \%)$ - GOLD III, in 4 (5,1\%) GOLD IV severity degrees, so 32 didn't receive any basic treatment at all.

4. At the same time among patients, in whose medical documentation was set the diagnosis of chronic obstructive pulmonary disease (COPD) only in 38,4 \% of cases it was spirographically verified, in other cases the hyperdiagnostics of this disease on the base of complaints and age characteristic took place.

5. Thus, a creation of easy screening algorithms of patients selection for the further spirographic examination that must become a routine one in not only pulmonologists' practice but in first turn in family doctor's one is urgent.

\section{References}

[1] Global Initiative for Chronic Obstructive Pulmonary Disease (2010). Global Strategy for the Diagnosis, Management, and Prevention of COPD. Available at: http://goldcopd.org/

[2] Agusti, A., Calverley, P. M., Celli, B., Coxson, H. O., Edwards, L. D. et. al. (2010). Characterisation of COPD heterogeneity in the ECLIPSE cohort. Respiratory Research, 11 (1), 122. doi: 10.1186/14659921-11-122

[3] Feshchenko, Yu., Yashina, L., Dzublik, A., Gavrisuk, V. (2011). Actual problems of treatment of patients with chronic obstructive pulmonary disease. Health Of Ukraine. Kyiv, 10-11.

[4] Bourbeau, J. (2010). Preventing Hospitalization for COPD Exacerbations. Seminars in Respiratory and Critical Care Medicine, 31 (3), 313-320. doi: 10.1055/s-0030-1254071

[5] Pro zatverdzhennya ta vprovadzhennya mediko-tekhnologichnyh dokumentiv zi standartyzatsii medychnoi dopomogy pry khronichnomu obstruktyvnomu zakhvoruvanni legen (2013). MOZ Ukrainy, No. 555. Available at: http://www.moz.gov.ua/ua/portal/dn_20130627_0555.html

[6] McDonough, J. E., Yuan, R., Suzuki, M., Seyednejad, N., Elliott, W. M., Sanchez, P. G. et. al. (2011). Small-Airway Obstruction and Emphysema in Chronic Obstructive Pulmonary Disease. New England Journal of Medicine, 365 (17), 1567-1575. doi: 10.1056/nejmoa1106955

[7] Feshchenko, Yu. (2010). Actual issues of chronic obstructive pulmonary disease. Ukrainian Pulmonology Journal, 1, 6-10.

[8] Hurst, J. R., Vestbo, J., Anzueto, A., Locantore, N., Mullerova, H., Tal-Singer, R. et. al. (2010). Susceptibility to Exacerbation in Chronic Obstructive Pulmonary Disease. New England Journal of Medicine, 363 (12), 1128-1138. doi: 10.1056/nejmoa0909883

[9] Kim, S. J. (2011). Chronic obstructive pulmonary disease (COPD) is associated with systemic inflammation. International Journal of Tuberculosis and Lung Disease, 15 (9), 1265-1270.

[10] Agusti, A. G. N. (2005). Systemic Effects of Chronic Obstructive Pulmonary Disease. Proceedings of the American Thoracic Society, 2 (4), 367-370. doi: 10.1513/pats.200504-026sr

[11] Pro zatverdzhennya ta vprovadzhennya mediko-tekhnologichnyh dokumentiv zi standartyzatsii medychnoi dopomogypry pry pynenni vzhyvannya tyutyunovykh vyrobiv (2012). MOZ Ukrainy, No. 601. Available at: http://www.moz.gov.ua/ua/portal/dn_20120803_601.html

[12] Rashton, L. (2007). Occupational causes of obstructive pulmonary disease. Reviews on Environmental Health, 22 (3), 195-212.

[13] Barnes, P. J. (2010). Chronic Obstructive Pulmonary Disease: Effects beyond the Lungs. PLoS Medicine, 7 (3), 100-102. doi: 10.1371/journal.pmed.1000220

[14] Mostovoy, Yu., Rasputina, L., Cherepiy, N. (2015). Diagnosis of symptoms of chronic obstructive pulmonary disease according to the survey. Medicine today and tomorrow, 2 (67), 59-65. 
[15] Linnyk, M. I., Nedospasova, O. V., Antonenko, L. F. (2010). Comparative data on the prevalence of respiratory diseases and medical care of patients with diseases of pulmonary profile in Ukraine in 2008-2010. Kyiv, 34.

[16] Rebrova, O. (2006). Statistical analysis of medical data. Application of software package STATISTICA. Moscow: Mediasfera, 312.

[17] Cherepiy, N. (2015). Diagnosis of risk factors for chronic obstructive pulmonary disease according to the survey of persons organized team. Visnyk VNMU, 19 (2), 448-452.

[18] Sidney, S., Sorel, M., Quesenberry, C. P., DeLuise, C., Lanes, S., Eisner, M. D. (2005). COPD and Incident Cardiovascular Disease Hospitalizations and Mortality: Kaiser Permanente Medical Care Program. Chest, 128 (4), 2068-2075. doi: 10.1378/chest.128.4.2068

[19] Hurd, S. S., Lenfant, C. (2005). COPD: good lung health is the key. The Lancet, 366 (9500), 1832-1834. doi: 10.1016/s0140-6736(05)67634-9

[20] National Heart Lung and Blood Institute (2009). Morbidity and Mortality: 2009 Chart Book on Cardiovascular, Lung, and Blood Diseases.Bethesda, National Heart, Lung, and Blood Institute. Available at: https://www.nhlbi.nih.gov 